\title{
Study of the Airborne Pollen and Spores in the Atmosphere of Alexandria City, Egypt
}

\section{Eman M Bassiouni ${ }^{1}$ and Wafaa K Taia ${ }^{2 *}$}

${ }^{1}$ Botany and Microbiology Department, Alexandria University, Alexandria, Egypt

${ }^{2}$ Faculty of Science, Department of Botany and Microbiology, Alexandria

University, Alexandria, Egypt

*Corresponding Author: Wafaa K Taia, Faculty of Science, Department of Botany and Microbiology, Alexandria University, Alexandria, Egypt.
Received: May 25, 2021

Published: June 11, 2021

(C) All rights are reserved by Eman $\mathbf{M}$

Bassiouni and Wafaa K Taia.

\section{Abstract}

This study deals with the investigation of both pollen grains and fungal spores trapped from the aerosol of Alexandria city. A Hirst type volumetric seven-day recording trap supplied by Burkrad Scientific (UK) was used and fixed at the University building in El-Shatby district 40m above ground. The results obtained throughout a full year, from May 2019 till April 2020, showed low annual pollen index of 378. The maximum records were in May and June 2019 as well as April 2020. The dominated species were Chenopodiaceae/Amaranthaceae complex, Casuarina, Arecaceae, Pinus and Utrica representing 9.6\%, 8.7\%, 6.7\%, 5.5\% and 4.9\% respectively. The fungal spores count was greater than the pollen grains as it showed 4176 annual spore index and dominated by Cladosporium, Alternaria and Aspergillus/Penicillium type (1216, 1133 and 319 respectively). While Beltrania, Tilletia, Pithomyces and Pleospora were the minimum counts. The maximum records were in June and July 2019, while the lowest counts were in January and February 2020. Correlation analyses of the results obtained with the climatic factors indicated that the pollen grains do not correlate with any climatic factors but depend on the phenology of the recorded species. The density of the fungal spores has positive correlation with both temperature and humidity. Pollen and spore approximate calendars for El-Shatby district in Alexandria city.

Keywords: Aeropalynology; Allergy; Fungal Spores; Pollen Grains; Pollinosis; Pollution

\section{Introduction}

In the recent years, air pollution, Anthropogenic Climate Change (ACC) beside Corona virus (COVID-19) consider from the most important crises facing the world [1,2]. These topics not only affect the environmental conditions and plant distribution, but also affect all the living organisms especially the human health and their mortality [3]. As mentioned by several works [1,2] the degree of the effect of air pollutants on human health and respiratory allergies depends on a combination of many factors such as components and concentrations of environmental pollutants, duration of exposure, ventilation, climatic conditions, and the interaction be- tween biotic and abiotic pollutants. From the most important biotic pollutants are fungal spores and pollen grains which are the main causes of hay fever $[4,5]$. These two micro-gametes react with the other pollutants causing allergic diseases and asthma. Sedghy., et al. (2018) explained the different proposals of these interactions as they might facilitate pollen allergen release, act as adjuvant to stimulate IgE-mediated responses, modify allergenic potential, and enhance the expression of some allergens inside the pollen grains [6]. The increase in the allergy potential of some pollen grains in the pollutant places was mentioned before by many authors such as Chehregani., et al. (2004), Motta., et al. (2006), Ghiani., et al. 
(2012) and Yoo and Perzanowski (2014) [7-10]. In fact, allergy considered from the widespread disease which mostly affects many peoples in the urbanized areas. Unfortunately, most the road trees of many cities proved to be allergenic and greater producers of pollen grains [11]. These road trees are planted in close proximity to humans, either at home, at work, or on their travel routes between locations. Taia., et al. (2019a) and Taia (2020) found that the pollen grains of some road trees are from the main causes of allergy $[12,13]$.

Not only pollen grains which stimulate allergic reactions, but also fungal spores. Crameri., et al. (2006) indicated that fungal spores present in both human body and environment are causes of allergic diseases in humans including allergic rhinitis, conjunctivitis, bronchial asthma and allergic broncho pulmonary mycoses [14]. Fungal spores disseminate in the environment through air, water, insects, man and even animals. Semik-Orzech., et al. (2008) pointed to the increase in allergic reactions to fungi using either skin test or specific IgE detection [15]. Several investigations $[16,17]$ reported that the most common fungal spores allergens are Alternaria, Cladosporium, Aspergillus, Penicillium and yeasts. While Sathavahana., et al. (2011) found that Penicillium, Aspergillus and Mucor are the widely distributed allergen fungal spores indoor South India [18].

Alexandria city is located in the western Mediterranean coastal region in Egypt (Figure 1). It has special weather, which characterizes by high humidity all over the year, moderate rainfall, and high temperature in summer and low in winter (Table 1). This investigation provides the pollen grains and fungal spores captured from the air during one full year in Alexandria, Egypt. This work considers as step forward in aeropalynological studies and identification of allergenic significant pollen grains and fungal spores in Alexandria. Meanwhile is to correlate between pollen grains and fungal spores concentration in the atmosphere and concurrent values of meteorological variables.

\section{Materials and Methods}

This study investigated the airborne pollen grains and fungal spores in the atmosphere of Alexandria, Egypt throughout the period from May 2019 till April 2020. A Hirst type volumetric sevenday recording trap supplied by Burkrad Scientific (UK) was used in the present study. The pollen trap was established on the roof of one of the buildings of Faculty of Science, Alexandria University, Egypt located in El-Shatby region. The building consists of 7 floors, and its height of about $40 \mathrm{~m}$.

Alexandria is the second largest city and a major economic center in Egypt. It is the country's largest seaport and the center of much of its maritime activity. Alexandria lies on the southern coast of the Mediterranean Sea in the north central part of the Egypt and is located between latitudes $31^{\circ} 12^{\prime} 56.30^{\prime \prime} \mathrm{N}$ and longitudes $29^{\circ} 57^{\prime} 18.97^{\prime \prime}$ E (Figure 1 and 2). Alexandria is considered one of the oldest cities in Egypt and lies around 225 kilometers northwest of Cairo (capital of Egypt). It is well known that Alexandria was established by Alexander the Great in around 332 BC.

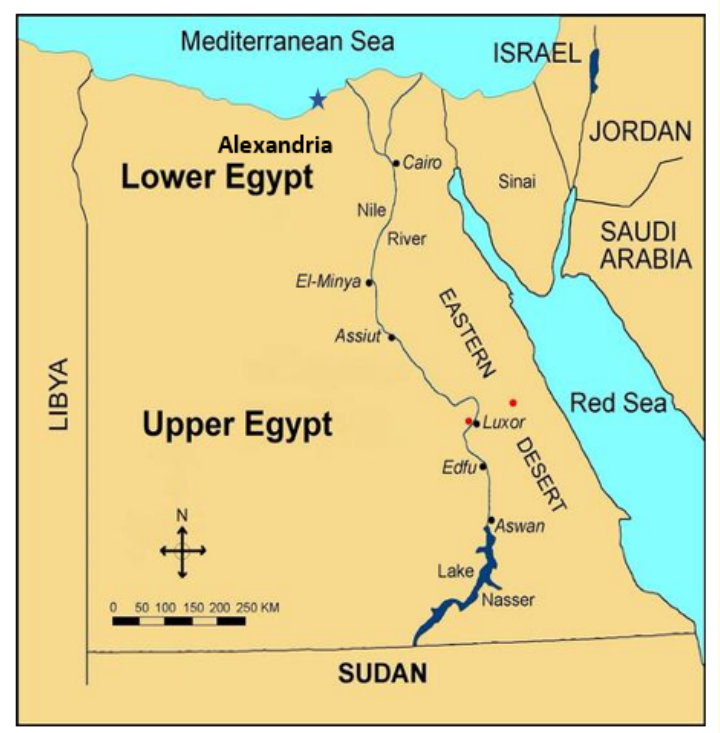

Figure 1: Location of the studied area, Alexandria in Egypt.

Data of the climate in the studied region during the period of study has been obtained from The Egyptian Meteorological Authority in Cairo, Egypt, El-Nozha station that covers an area of radius equal to $50 \mathrm{~km}$ including the studied area. From the data listed in table 1 , we found that the air contains high relative humidity throughout the whole year. The rainfall was during December and January, while the temperature varied between the four seasons and between day and night of the same day (Figure 3). 


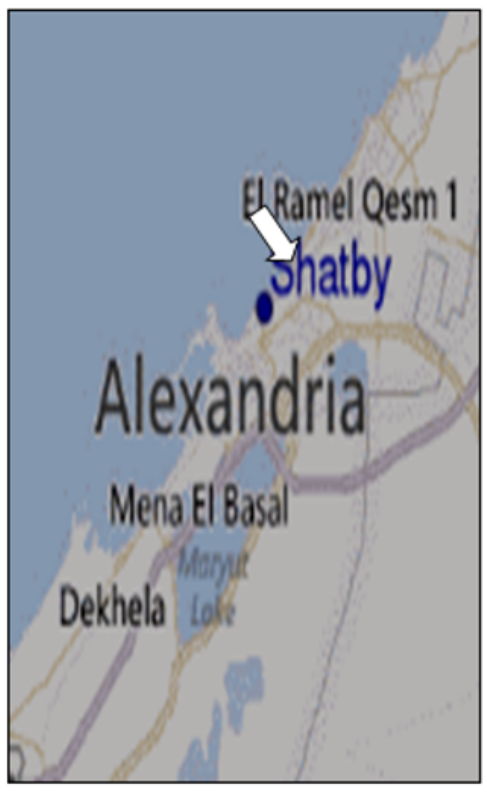

Figure 2: Location of the studied area in Alexandria.

The trap contains a vacuum pump that draws $10 \mathrm{l} / \mathrm{min}$ airflow via an orifice which is oriented towards the wind all the time. Pollen grains and spores present in the atmosphere were impacted on an adhesive coated transparent plastic tape. The Melinex tape is fixed on a drum which is driven by a 7-jewel clockwork movement. The mechanism of work involves that the drum rotated past the orifice at $2 \mathrm{~mm} /$ hour, and it is changed weekly [19]. In this study, the sampling method used by Hirst 1952 was followed. The plastic tape is firstly coated with $10 \%$ gelvatol and after that the adhesive mixture (Vaseline and wax) is added. Then it fixed in a drum with a known circumference. After one week of exposure, the tape was cut into $48 \mathrm{~mm}$ or 24 hours segments. Each segment representing one day was put on a slide, and glycerin jelly stained with basic fuchsin was used as a mounting medium. Light microscope fitted with camera and computer software was used for examination. The methodology followed by Spanish Aerobiology Network, REA [20] was used as four longitudinal horizontal sweeps per slide were counted at magnification of $400 \mathrm{x}$. Pollen and spore counts are indicated as the daily mean count per cubic meter of air. The examined slides were prepared and preserved in Botany and Microbiology Department, Faculty of Science, Alexandria University. Throughout one full year, approximations to pollen/spore calendars were designed by following Spieksma's model [21]. Such a model expresses 10day mean pollen concentrations into a series of classes indicated by columns of increasing height. In the present study, only those dominant pollen grains and fungal spores with minimum 10-day mean equal to or greater than 0.1 pollen grains(spores) $/ \mathrm{m}^{3}$ of air are included.

\section{Results}

\section{A-Pollen Grains}

The data obtained show annual pollen index throughout the study period, from May 2019 till April 2020, was 378. This showed a maximum monthly pollen count in May, June2019 and April 2020

\begin{tabular}{|l|c|c|c|c|c|c|c|c|c|c|c|c|}
\hline \multicolumn{1}{|c|}{ Month } & May-19 & Jun-19 & Jul-19 & Aug-19 & Sep-19 & Oct-19 & Nov-19 & Dec-19 & Jan-20 & Feb-20 & Mar-20 & Apr-20 \\
\hline $\begin{array}{l}\text { Max. Temperature } \\
\left({ }^{\circ} \mathrm{C}\right)\end{array}$ & 33.2 & 30.2 & 34.1 & 31.9 & 30.6 & 28.8 & 27.2 & 19.1 & 16.7 & 19.4 & 23.4 & 28.3 \\
\hline $\begin{array}{l}\text { Mini. Temperature } \\
\left({ }^{\circ} \mathrm{C}\right)\end{array}$ & 17.5 & 23.2 & 24.3 & 23.5 & 22.2 & 20.5 & 16.7 & 12.2 & 10.8 & 10.8 & 12.3 & 14.9 \\
\hline $\begin{array}{l}\text { Average } \\
\text { Temperature }\left({ }^{\circ} \mathrm{C}\right)\end{array}$ & 25.35 & 26.7 & 29.2 & 27.7 & 26.4 & 24.65 & 21.95 & 15.65 & 13.75 & 15.1 & 17.85 & 21.6 \\
\hline $\begin{array}{l}\text { Relative Humidity } \\
(\%)\end{array}$ & 50 & 64 & 61 & 65 & 55 & 62 & 61 & 64 & 72 & 67 & 59 & 55 \\
\hline $\begin{array}{l}\text { Total Rainfall } \\
(\mathrm{mm} / \text { month) }\end{array}$ & 0 & 0 & 0 & 0 & 0 & 63.2 & 0 & 106.5 & 163.3 & 36 & 39.6 & 1.3 \\
\hline
\end{tabular}

Table 1: Climatology (from May 2019 to April 2020). 


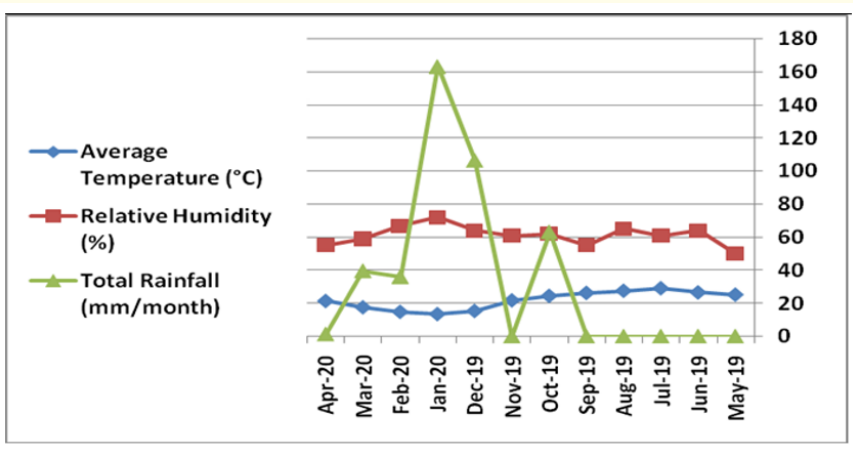

Figure 3: Average temperature, relative humidity and total rainfall in the studied area in Alexandria during the period of study.

(99, 62 and 64 pollen grains $/ \mathrm{m}^{3}$ respectively, Figure 4). While the lowest monthly pollen count was found in October 2019 and January 2020 with a value of 4 pollen grains $/ \mathrm{m}^{3}$, Figure 4 ). We identified ten types of pollen grains; the highest records were of Chenopodiaceae/Amaranthaceae complex, Casuarina, Arecaceae, Pinus and Utrica representing 9.6\%, 8.7\%, 6.7\%, 5.5\% and 4.9\% respectively, table 2. Apiaceae and Myrtaceae considered the rare families (Plate 1, Photos 1 and 7 respectively). An approximation to a pollen calendar is set up for the eight dominant taxa during the year of study (Figure 5).

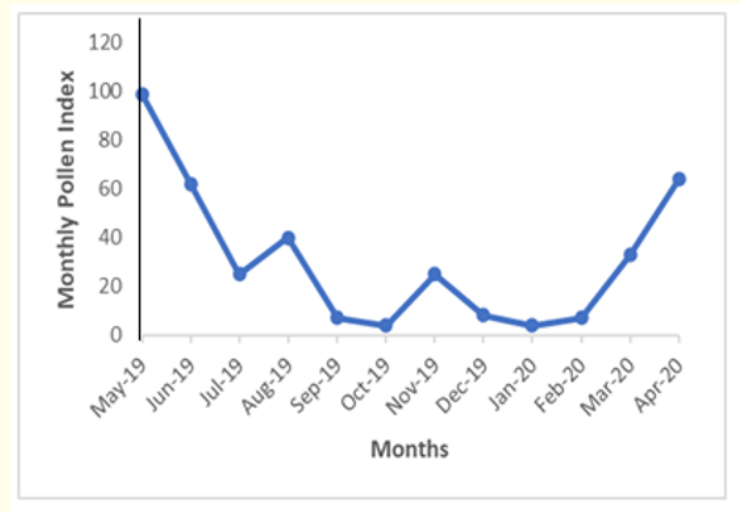

Figure 4: Monthly pollen index during the period from May 2019 to April 2020 in Alexandria, Egypt.
The following taxa, arranged alphabetically, show the details of pollen grains count and descriptions during the studied period as summarized in table 2 and figure 5.

\section{Apiaceae (Plate 1 Photo 1a and 1b)}

Pollen of the Apiaceae was restricted in May and June 2019 with very low percentage, $0.6 \%$ (Table 2 ). The pollen isisopolar, radiosymmetric, medium in size $(33.2 \times 12.8 \mu \mathrm{m})$, perprolate $(\mathrm{PA} / \mathrm{EA}=$ $2.5)$, tricolporate, with long colpi and endoaperture widelolongate, exine tectatemicroreticulate.

\section{Arecaceae (Plate 1, Photo 2a and 2b)}

This pollen type represents the third largest family in this study with $6.7 \%$ as shown in table 2 . It is appeared that Arecaceae pollen restricted only in March, April and May with the highest peaks in the first and last decades of April (Figure 5). The pollen isheteropolar, bilateral symmetricelliptic to spherical, medium in size(18.5$44.5 \mu \mathrm{m})$, monosulcate and exine tectate punctuate.

\section{Asteraceae (Plate 1, Photo 3a and 3b)}

Pollen of Asteraceae account for moderate amounts (3.5\%) which is found mainly in the last decade of August. The pollen isapolar, radiosymmetric, spherical, small in size $(25-36 \mu \mathrm{m})$, tricolporate, with long colpi and wide lolongateendoaperture and exine tectate granulate.

\section{Casuarina (Plate 1, Photo 4a and 4b)}

As appeared in figure 5, Casuarina pollen was distributed throughout the studied period except few months with annual pollen index equals to $8.7 \%$, which is considered the second largest taxa. In more focus, the greatest values detected in the second decade of November and the first decade of March. The pollen isapolar, radiosymmetric, oblate spheroidal, small in size $(25.5 \times 28.5$ $\mu \mathrm{m})$, triporate with small pores and exine tectate granulate.

\section{Chenopodiaceae/Amaranthaceae complex (Plate 1, Photo 5a and 5b)}

In the present study, the greatest amounts of pollen grains come from Chenopodiaceae/Amaranthaceae complex with 9.6\%.This pollen type distributed mainly from March until August with the highest peak in the third decades of August (Figure 5). The pollen isapolar, radiosymmetric, spherical, small in size $(25-32 \mu \mathrm{m})$, pantoporate with small echinated pores and exine tectate echinate. 


\section{Cupressaceae (Plate 1, Photo 6a and 6b)}

Cupressaceae contributed with a moderate percent of pollen grains up to $4.4 \%$. This pollen kind distributed around half of the year with the maximum records in the first decade of December (Figure 5). The pollen isapolar, radiosymmetric, spherical, medium in size $(32-48 \mu \mathrm{m})$, aporate and exine tectate granulate.

\section{Myrtaceae (Plate 1, Photo 7a and 7b)}

Pollen of the Myrtaceae found in May 2019, March and April 2020 by very few incidences, it represents $1.2 \%$. The pollen isiso-

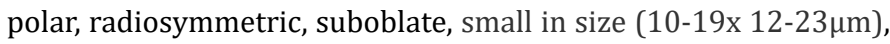
tricolporate with long colpi and lolongateendoaperture and exine tectatescabrate.

\section{Pinus (Plate 1, Photo 8a and 8b)}

Pollen of Pinus shared with moderate amounts up to $5.5 \%$ from the total assemblage intensified mostly in June. The pollen is heteropolar, bilateral symmetric, oblate, medium in size $(88.6 \mathrm{x}$
$57.1 \mu \mathrm{m})$, with one leptoma on distal pole and the bladders with a reticulate pattern.

\section{Poaceae (Plate 1, Photo 9a and 9b)}

This study indicates that Poaceae pollen shared with moderate amounts in the air of Alexandria during the period of study that account for $3.2 \%$. There is no specific period that shows greatest values throughout the year. The pollen is heteropolar, bilateral symmetric, spherical, folded or irregular, small in size (10-21 $\mu \mathrm{m})$, monoporate with small annulate and centrally plugged pore and exine tectate granulate.

\section{Utrica (Plate 1, Photo 10a and 10b)}

The pollen of Urtica contributes with $4.9 \%$ from the total pollen assemblage, which is concentrated during spring and summer months. The pollen is radio symmetric, apolar, oblate-spheroidal, small from $12.0-16.0 \mu \mathrm{m}$. The grains have from two to four circular annulate pores with elevated lips, exine tectate granulate.

\begin{tabular}{|c|c|c|c|c|c|c|c|c|c|c|c|c|c|c|}
\hline $\begin{array}{l}\text { Month } \\
\text { Pollen }\end{array}$ & May-19 & Jun-19 & Jul-19 & Aug-19 & Sep-19 & Oct-19 & 9 Nov-19 & 9 Dec-19 & Jan-20 & Feb-20 & Mar-20 & Apr-20 & $\mid \begin{array}{l}\text { Yearly } \\
\text { influx }\end{array}$ & Percentage \\
\hline Apiaceae & 1 & 1 & 0 & 0 & 0 & 0 & 0 & 0 & 0 & 0 & 0 & 0 & 2 & 0.6 \\
\hline Arecaceae & 4 & 0 & 0 & 0 & 0 & 0 & 0 & 0 & 0 & 0 & 2 & 17 & 23 & 6.7 \\
\hline Asteraceae & 0 & 0 & 0 & 11 & 1 & 0 & 0 & 0 & 0 & 0 & 0 & 0 & 12 & 3.5 \\
\hline Casuarina & 5 & 2 & 0 & 1 & 0 & 0 & 6 & 0 & 1 & 0 & 12 & 3 & 30 & 8.7 \\
\hline $\begin{array}{l}\text { Chenopodiaceae/ } \\
\text { Amaranthaceae } \\
\text { complex }\end{array}$ & 9 & 1 & 2 & 10 & 1 & 0 & 2 & 0 & 0 & 0 & 4 & 4 & 33 & 9.6 \\
\hline Cupressaceae & 1 & 2 & 0 & 0 & 0 & 1 & 0 & 6 & 1 & 0 & 1 & 3 & 15 & 4.4 \\
\hline Myrtaceae & 2 & 0 & 0 & 0 & 0 & 0 & 0 & 0 & 0 & 0 & 0 & 2 & 4 & 1.2 \\
\hline Pinus & 2 & 13 & 0 & 1 & 0 & 0 & 0 & 0 & 0 & 0 & 1 & 2 & 19 & 5.5 \\
\hline Poaceae & 0 & 1 & 0 & 1 & 0 & 2 & 2 & 1 & 0 & 2 & 1 & 1 & 11 & 3.2 \\
\hline Urtica & 1 & 5 & 1 & 1 & 0 & 0 & 0 & 0 & 0 & 1 & 1 & 7 & 17 & 4.9 \\
\hline $\begin{array}{l}\text { Unidentified } \\
\text { pollen }\end{array}$ & 74 & 37 & 22 & 15 & 5 & 1 & 15 & 1 & 2 & 4 & 11 & 25 & 212 & 61.6 \\
\hline Monthly influx & 99 & 62 & 25 & 40 & 7 & 4 & 25 & 8 & 4 & 7 & 33 & 64 & 378 & \\
\hline
\end{tabular}

Table 2: Monthly pollen index spanning the period from May 2019 to July 2020 in Alexandria, Egypt. 


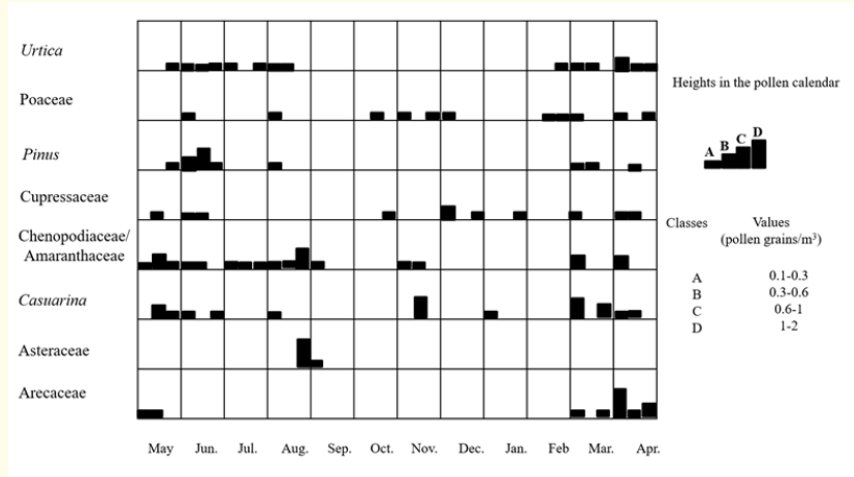

Figure 5: An approximate pollen calendar for Alexandria, using data from May 2019 to April 2020. Classes and pollen concentration values are represented in the calendar.

\section{B-Fungal spores}

The annual spore index recorded in the air of Alexandria during the studied period spanning from May 2019 until April 2020 was 4176. This count belongs mainly to 15 spore types of fungal genera as mentioned in table 3. June and July 2019 represent the greatest counts of fungal spores during the study period; 906 and 829 respectively (Table 3 and figure 6). On the other hand, the lowest counts were in January and February 2020 (32 and 29 spores $/ \mathrm{m}^{3}$ of air respectively, table 3 ). The maximum spore records obtained from Cladosporium and Alternaria (1216 and 1133 respectively). While Beltrania, Pithomyces, Pleospora and Tilletia represent the lowest spore counts during the study period (Plate 2, Photos 4, 12, 13 and 15 respectively). So, an approximation to a fungal spore calendar is designed to eleven spore types (Figure 7).

The records below are the most representative types of fungal spores present in alphabetic order and summarized in table 3 and illustrated in figure 6 and 7.

\section{Alternaria (Plate 2, Photo 1)}

Spores of Alternaria come in the second order among other identified fungal spores in term of abundance. The total count for this genus is 1133 spores $/ \mathrm{m}^{3}$ (28.1\%, table 3$)$. These spores distributed almost in the whole year with high records.

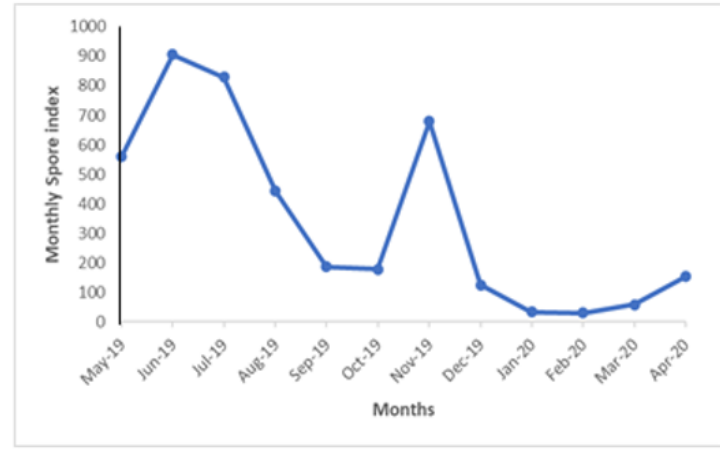

Figure 6: Monthly spore index during the period from May 2019 to April 2020 in Alexandria, Egypt.

\section{Ascospores (Plate 2, Photo 2)}

This group of fungal spores belonging to Ascomycetes was found during the studied period with very low incidence, just account for $1.1 \%$ of the total record.

\section{Aspergillus/Penicillium-type (Plate 2, Photo 3)}

These spores distributed throughout the whole year and account for 319 spore $/ \mathrm{m}^{3}$ of air (7.9\%) and showed the highest peak in the second decade of June (Figure 7).

\section{Chaetomium (Plate 2, Photo 5)}

This spore kind recorded with relatively few amounts all over the study period. It covers $1.6 \%$ from the total assemblage. The highest peaks are detected in the second and third decades of May 2019 (Figure 7).

\section{Cladosporium (Plate 2, Photos 6 and 7)}

Cladosporium spores are the biggest record among all the incident spores in Alexandria. The annual spore influx of this species was 1216 (30.1\%). They were recorded with high percent from May 2019 until the first decade of November 2019.

\section{Curvualria (Plate 2, Photo 8)}

The annual spore index of Curvualria is relatively few equal to 33 spores $/ \mathrm{m}^{3}(0.8 \%)$. This spore kind distributed almost half of the year with the greatest peak in the second decade of November 2019 (Figure 7). 


\begin{tabular}{|c|c|c|c|c|c|c|c|c|c|c|c|c|c|}
\hline $\begin{array}{l}\text { Month } \\
\text { Spores }\end{array}$ & May-19 & Jun-19 & Jul-19 & Aug-19 & Sep-19 & Oct-19 & Nov-19 & Dec-19 & Jan-20 & Feb-20 & Mar-20 & Apr-20 & $\begin{array}{l}\text { Yearly } \\
\text { influx }\end{array}$ \\
\hline Alternaria & 186.84 & 245.7 & 262.44 & 117.72 & 35.1 & 31.86 & 173.34 & 1.32 & 3.24 & 3.24 & 10.8 & 31.86 & 1133.46 \\
\hline Ascospores & 2.7 & 2 & 0 & 54 & 2.16 & 2.7 & 9.18 & 9.18 & 6.48 & 2.16 & 5.94 & 0 & 43.74 \\
\hline $\begin{array}{c}\text { Aspergillus/ } \\
\text { Penicillium-type }\end{array}$ & 31.86 & 92.34 & 43.74 & 41.04 & 17.28 & 10.8 & 44.28 & 0 & 0 & 5.4 & 1.62 & 30.78 & 319.14 \\
\hline Beltrania & 0 & 0.54 & 0 & 0 & 0 & 0 & 1.08 & 0 & 0 & 0 & 0 & 0 & 1.62 \\
\hline Drechslera-type & 11.34 & 4.86 & 9.18 & 6.48 & 1.62 & 9.18 & 19.98 & 4.32 & 0 & 0 & 0 & 0 & 66.96 \\
\hline Chaetomium & 27 & 4.86 & 4.86 & 2.16 & 0.54 & 2.7 & 9.72 & 0.54 & 1.08 & 0.54 & 2.7 & 3.78 & 60.48 \\
\hline Cladosporium & 42.66 & 413.1 & 368.28 & 145.8 & 50.76 & 43.74 & 119.34 & 3.78 & 1.08 & 0.54 & 1.08 & 24.84 & 1215 \\
\hline Curvularia & 2.16 & 0 & 2.16 & 2.7 & 3.78 & 2.16 & 15.66 & 2.16 & 0.54 & 0 & 0 & 0.54 & 31.86 \\
\hline Epicoccum & 2.7 & 8.64 & 5.94 & 1.08 & 0.54 & 0 & 3.24 & 0 & 0 & 0 & 0 & 0.54 & 22.68 \\
\hline Mycosphaerella & 8.64 & 1.08 & 2. & 2.7 & 2.16 & 5.94 & 29.16 & 26.46 & 8.1 & 6.48 & 4.32 & 2.7 & 100.44 \\
\hline Pithomyces & 3.24 & 0 & 3.24 & 0 & 0 & 0 & 0 & 0.54 & 0 & 1.62 & 0.54 & 2.16 & 11.34 \\
\hline Pleospora & 2.7 & 1.08 & 0 & 0.54 & 0.54 & 0 & 1.08 & 0.54 & 0 & 0 & 0 & 3.78 & 10.26 \\
\hline Stemphylium & 54 & 8.64 & 13.5 & 3.78 & 0.54 & 1.62 & 14.04 & 4.32 & 0.54 & 0 & 14.04 & 7.54 & 122.56 \\
\hline Tetraploa & 0 & 0 & 0 & 0 & 0 & 0 & 0 & 0 & 0 & 0 & 0 & 0 & 0 \\
\hline Tilletia & 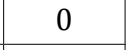 & 0.54 & 3.78 & 2.7 & 0 & . & 0 & 0 & 0 & 0 & 0 & 0 & 7.02 \\
\hline Torula & 24.84 & 8.1 & 3.24 & 5.4 & 0.54 & 1.08 & 1.08 & 0 & 0 & 0 & 0 & 3.78 & 48.06 \\
\hline $\begin{array}{l}\text { Unidentified } \\
\text { fungal spores }\end{array}$ & 158.76 & 111.78 & 105.52 & 109.08 & 66.96 & 63.72 & 239.22 & 42.12 & 10.8 & 8.64 & 15.64 & 36.72 & 968.96 \\
\hline Monthly influx & 559.44 & 903.96 & 828.58 & 441.72 & 182.52 & 175.5 & 680.4 & 125.28 & 31.86 & 28.62 & 56.68 & 149.02 & 4163.58 \\
\hline
\end{tabular}

Table 3: Monthly fungal sporeindex spanning the period from May 2019 to April 2020 in Alexandria, Egypt.

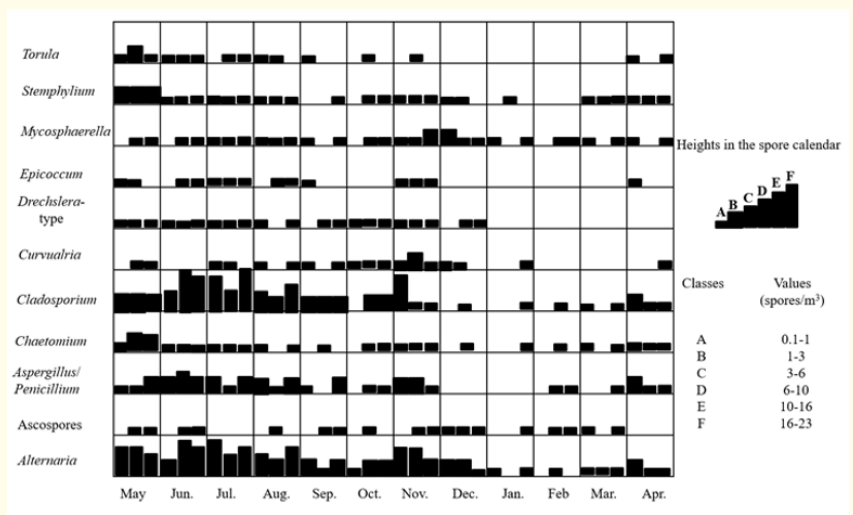

Figure 7: Fungal spores calendar for Alexandria, using data from May 2019 to April 2020. Classes and spore concentration values are represented in the calendar.

\section{Drechslera-type (Plate 2, Photo 9)}

This spore detected mostly from May 2019 until December 2019. Its record is considerably small like Chaetomium with $1.6 \%$ from the total assemblage counts.

Epicoccum (Plate 2, Photo 10)

The total count of this spore is relatively few, it was $0.6 \%$ from the whole record recorded during half of the year.

\section{Mycosphaerella (Plate 2, Photo 11)}

The annual spore influx of this species was 100 accounting for $2.5 \%$ from the total assemblage. They occurred all over the studied period with highest peaks in the third decade of November 2019 and the first decade of December 2019 (Figure 7).

\section{Stemphylium (Plate 2, Photo 14)}

Spores of Stemphylium were distributed almost throughout the whole year with the greatest records in May 2019. These spores 
represented by $3.1 \%$ of the total record of the airborne fungal spores.

\section{Torula (Plate 2, Photo 16)}

Torula spores present in considerably small amount, it comprises up to $1.2 \%$, from the total record. These species restricted in half of the year and show the highest peak in the second decade of May (Figure 7).

Variation between major climatic data and pollen and spore incidence

Variations in the monthly pollen grain incidences in relation to the average temperature, relative humidity and total rainfall have been illustrated in figure 8 . The highest records of the pollen grains were during May 2019 and April 2020, with another lower peak during August and November 2019. This result is in negative correlation with the rainfall and did not affect by both temperature and air relative humidity. In contrary, during the rainy months; October and December 2019, and January and February 2020; the pollen grain counts were few.

Fungal spores count was higher than those of pollen grains. From figure 9 we found that the higher counts were during the summer period from May till August 2019 and decreased during autumn with an increase again during November 2019 and start to increase again from March to April 2020. This record did not correlate with the meteorological data, but partially affected with the increase in temperature. During the dry months, the fungal spore count maximized, while the rainy months have no effect on their counts.

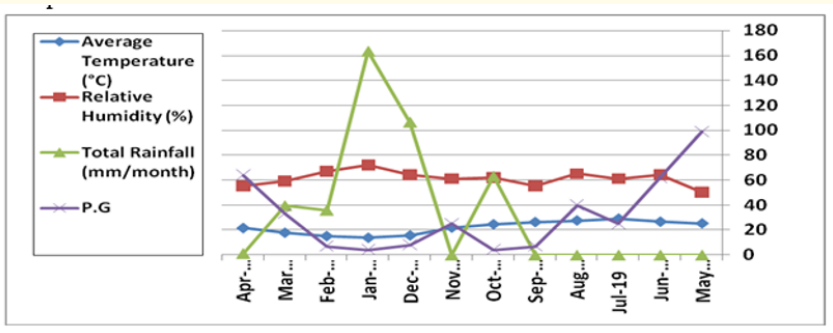

Figure 8: Variations in the monthly pollen grains incidences in relation to the average temperature, relative humidity and total rainfall.

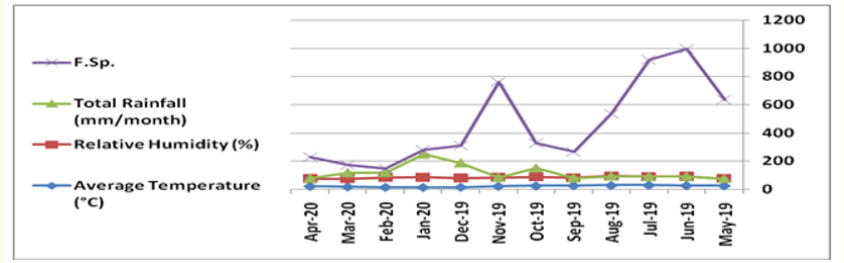

Figure 9: Variations in the monthly fungal spores incidences in relation to the average temperature, relative humidity and total rainfall.

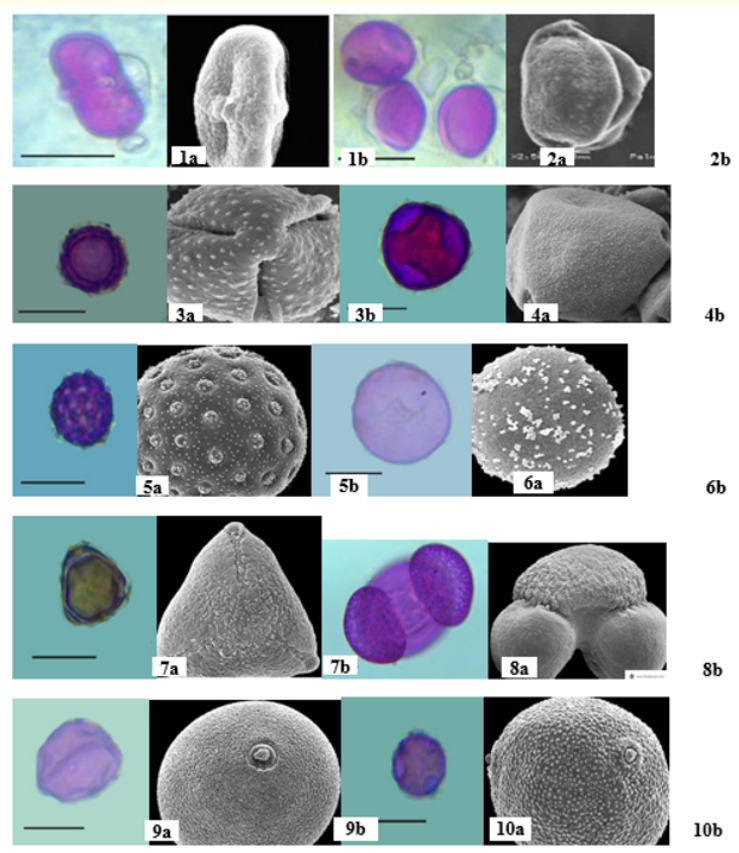

Plate 1: Pollen Grains (Scale bar $=20 \mu \mathrm{m}$ ) a = light microscope, $\mathrm{b}=$ SEM photographs, 1 Apiaceae; 2 . Arecaceae; 3 . Asteraceae; 4. Casuarina sp.; 5. Chenopodiaceae/Amaranthaceae; 6. Cupressaceae; 7. Myrtaceae; 8. Pinus sp.; 9. Poaceae; 10. Urtica sp.

\section{Discussion}

The pollen grains dispersed by air, considered from the most important reason causing allergy. The process of pollination is normal in all plants to complete their life cycle. During this process 

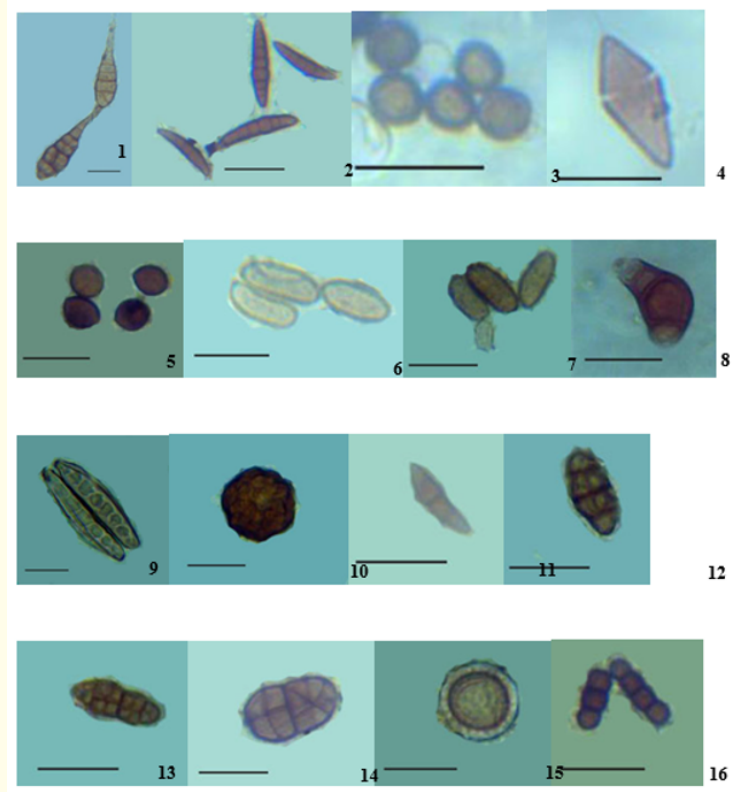

Plate 2: Fungal spores (Scale bar $=20 \mu \mathrm{m})$ : 1. Alternaria sp.;

2. Ascospores; 3. Aspergillus/Penicillium-type; 4. Beltrania sp.; 5. Chaetomium sp.; 6, 7. Cladosporium spp.; 8. Curvularia sp.; 9. Drechslera-type; 10. Epicoccum sp.; 11. Mycosphaerella sp.; 12. Pithomyces sp.; 13. Pleospora sp.;14. Stemphylium sp.; 15. Tilletia sp.; 16. Torula sp.

thousands of pollen grains carried by air and cause severe symptoms to sensitive peoples. Alexandria, which is located in the Southern Mediterranean coastal strip, has its special climate which sensitizes most of the peoples living in it. This climate stimulates Saad $(1958 a, b)$ to be the first study on the aeropalynology in the city $[22,23]$. Since that time, lot of changing in the vegetation around the city due to industrialization and urbanization happened and also, the air affected by many pollutants. El-Ghazaly., et al. (1991) started the second work about the airborne pollen grains and fungal spores in Alexandria [24]. They found that the duration of pollen-free atmosphere in Alexandria is very short occurs only in January and part of February. Our result showed longer periods of scarce pollen in Alexandria air during September, October, December 2019 and January and February 2020. This long period of pollen free air in Alexandria coordinates with that obtained by Saad (1958a and b) $[22,23]$. The rainy months have little amount of pollen grains in the air due to the washing down of the pollen grains. Our record showed that from March to April the air contains more pollen grains than the rest of the year; this result coordinates with those found in both southern Spain [25] and Turkey [26].

In this work, the pollen grains of the anemophilous trees are the most common trapped ones. The Arecaceae, Casuarina, Cupressus and Pinus pollen grains are the most abundant anemophilous tree trapped pollen in Alexandria; 6.7\%, 8.7\%, 4.4\% and 5.5\% respectively; these pollen grains are small sized, light and can travel for miles in the air. These taxa were partially similar to that obtained by El-Ghazaly., et al. (1991) [24]. Agashe., et al. (1994), Garcia., et al. (1997) and Burton and Katelaris (2007) found that Casuarina pollen grains reflect sensitization skin prick test causing allergy to sensitive peoples [27-29]. Serhane., et al. (2017) reported that the date palm pollen grains cause allergy, as their rate of sensitization is between 6 and 29\% [30]. Concerning the travelling of both pollen grains and fungal spores, Damialis., et al. (2017) found that there are abundant of both at elevation more than 2,000 meters above sea level [31]. This means that air can carry them to high levels causing allergic symptoms.

From the most abundant pollen grains of herbs; in the air of Alexandria; are those of Chenopodiaceae-Amaranthaceae complex (9.6\%) and Utrica (4.9\%). These types of pollen grains proved their allergenicity by many authors $[12,25,32,33]$. These herbs are common wild herbs distributed in Alexandria streets, roadsides, even beside the railways. Tiotiu., et al. (2016) found that the exposure to Urtica pollen can induce allergic reactions [34]. Chenopodium album and Utricaurens have itching hairs as well and their pollen has excess protein and mineral contents which may cause pollinosis [13].

The aerosol of Alexandria city does not include pollen grains only, fungal spores were recorded in high amount, 4176 Y Influx. Fungal spores trapped from the air throughout the studied period, and they exceed the pollen counts by hundreds of times that depends on environmental factors, such as water, nutrients, temperature and wind $[35,36]$. In this study, the record of the fungal spores was great from May till August and increased again in November 2019. This can be attributed to the presence of vegetable and fruit market near the place of study, beside the trees around the build- 
ing. The main fungal spore was Cladosporium (30.1\%), Alternaria (28.1\%) and Aspergillus/Penicillium type (7.9\%), beside other fungal spore types in fewer amounts. These types of fungal spores in Alexandria and Rosetta aerosol were reported by El-Ghazaly., et al. (1991) and Taia., et al. (2019b) respectively [17,24]. Gómez de Ana., et al. (2006) considered the spores of Alternaria, Aspergillus, Cladosporium and Penicillium as allergenic [37], while Damialis and Gioulekas (2006) found that both Cladosporium and Alternaria are the main fungal spores in the aerosol of Greece and those of Cladosporium were influenced by solar radiation while Alternaria spores were affected by air temperature [38]. Menetrez., et al. (2007) found that the fungal spores correlated with the organic carbon concentration, and they carry harmful substances causing allergy [39]. Fukutomi and Taniguchi (2015) indicated to the allergic effects of Alternaria and Cladosporium spores [40]. All these works, beside many, indicated to the allergic effect of these fungal spores and coincide with our results.

The relation between both pollen grains and fungal spores with the climatic factors reveals that there is no correlation between the pollen grains and the different climatic factors. Sabo., et al. (2015) found that there is positive correlation between air pollen grains of anemophilous species and the degree of temperature, while the correlation was negative with the humidity and cloud index. The results obtained are not coordinate with those obtained by Sabo., et al. (2015) as the pollen counts did not affect by either temperature or humidity and negatively correlated with the rainfall [41]. This can be explained by the washing up process of the air by the rain. Meanwhile there is great positive correlation between fungal spores and temperature. This correlation was mentioned before by Beguin and Nolard (1994) who found that the high incidence of fungal spores during summer is due to the presence of nutrients in the soil, favorable temperature and humidity [42]. Andersson., et al. (2003) reported that the airborne concentrations of Alternaria spores were high in the summer than in winter [43]. These observations coincide with our results.

\section{Conclusion}

From this study, we can conclude that the aerosol of Alexandria city carries few amounts of pollen grains, and the present types are mostly of anemophilous trees beside both Amaranthaceae-Chenopodiaceae type and Utrica sp. The density of the pollen grains does not correlate with any climatic factors but depend on the phenol- ogy of the recorded species. The density of the fungal spores is greater than that of the pollen grains due to the presence of fungi everywhere and the spore dispersal happens the whole years. The fungal spores have positive correlation with both temperature and humidity.

\section{Bibliography}

1. D'Amato G., et al. "Urban air pollution and climate change as environmental risk factors of respiratory allergy: an update". Journal of Investigational Allergology and Clinical Immunology 20.2 (2010): 95-102.

2. D'Amato G. "Effects of climatic changes and urban air pollution on the rising trends of respiratory allergy and asthma". Multidisciplinary Respiratory Medicine 6.1 (2011): 28-37.

3. Zhang Q., et al. "Link between environmental air pollution and allergic asthma: East meets West". Journal of Thoracic Disease 7.1 (2015): 14-22.

4. Leuschner R H., et al. "30 Years of study of grass pollen in Basel, Switzerland". Aerobiologia 16 (2000): 381-391.

5. García-Mozo H., et al. "Airborne pollen sampling in Toledo, Central Spain". Aerobiologia 22 (2006): 55-66.

6. Sedghy F., et al. "Interaction between air pollutants and pollen grains: The role on the rising trend in allergy". Reports of Biochemistry and Molecular Biology 6.2 (2018): 219-224.

7. Chehregani A., et al. "Increasing allergy potency of Zinnia pollen grains in polluted areas". Ecotoxicology and Environmental Safety 58.2 (2004): 267-272.

8. Motta AC., et al. "Traffic-related air pollutants induce the release of allergen-containing cytoplasmic granules from grass pollen". International Archives of Allergy and Immunology 139.4 (2006): 294-298.

9. Ghiani A., et al. "Ragweed pollen collected along high-traffic roads shows a higher allergenicity than pollen sampled in vegetated areas". Allergy 67.7 (2012): 887-894.

10. Yoo Y and Perzanowski MS. "Allergic sensitization and the environment: latest update". Current Allergy and Asthma Reports 14.10 (2014): 1-9. 
11. Thompson J L and Thompson J E. "The urban jungle and allergy". Immunology and Allergy Clinics of North America 23.3 (2003): 371-87.

12. Taia WK., et al. "Study of the airborne pollen grains in Rosetta, Egypt". International Journal of Advanced Research and Publications (IJARP) 3.3 (2019a): 122-129.

13. Taia WK. "Pollen allergens of some road trees, shrubs and herbs in Alexandria, Egypt". Journal of Biomedical Sciences (OAJBS) 1.5 (2020): 187-194.

14. Crameri R., et al. "Fungal allergies: yet unsolved problem". Chemical Immunology and Allergy 91 (2006): 121-133.

15. Semik-Orzech A., et al. "The influence of sensitivity to fungal allergens on the development and course of allergic diseases of the respiratory tract". Pneumonologia i alergologia polska 76 (2008): 29-36.

16. Bogacka E and Jahnz-Rozyk K. "Allergy to Fungal antigens". Polski Merkuriusz Lekarski 14 (2003): 381-384.

17. Taia WK., et al. "Study of the airborne fungal spores in Rosetta, Egypt". European Journal of Experimental Biology 9.1 (2019b): 4.

18. Sathavahana C V., et al. "Role of Fungi (molds) in allergic airway disease-An Analysis in a South Indian Otolaryngology center". Indian Journal of Allergy, Asthma and Immunology 25.2 (2011): 67-78.

19. O'Rourke M K. Chapter 23F. Medical palynology; in Jansonius, J. and McGregor, D. C. (ed.), Palynology; principles and applications. American Association of Stratigraphic Palynologists Foundation 3 (1996): 945-955.

20. Galán C., et al. "Spanish Aerobiological Network (REA): Management and Quality Manual". Ed. Córdoba: Servicio de Publicaciones de la Universidad de Córdoba, Spain (2007).

21. Spieksma F. "Regional European pollen calendars". In G. D’Amato, F. Th. M. Spieksma, and S. Bonini (Eds.), Allergenic pollen and pollinosis in Europe. Oxford: Blackwell Sci. Publ (1991): 49-65.
22. Saad S I. "Studies in atmospheric pollen grains and fungus spores at Alexandria. I. A daily census of pollen". Egyptian Journal of Botany 1 (1958a): 53-61.

23. Saad S I. "Studies in atmospheric pollen grains and fungus spores at Alexandria. II. Pollen and spores deposition in relation to weather conditions and diurnal variation in the incidence of pollen". Egyptian Journal of Botany 1 (1958b): 63-79.

24. El-Ghazaly., et al. "Study of aerobiology of Alexandria, Egypt". Qatar University Science Journal 11 (1991): 161-182.

25. Docampo S., et al. "Risk of pollen allergy in Nerja (southern Spain): a pollen calendar". Aerobiologia 23 (2007): 189-199.

26. Türe $\mathrm{C}$ and Böcük $\mathrm{H}$. "Analysis of airborne pollen grains in Bilecik, Turkey". Environmental Monitoring and Assessment 151 (2009): 27-35.

27. Agashe S N., et al. "Aerobiology of Casuarina pollen and its significance as a potential aeroallergen". Aerobiologia 10.2 (1994): 123-128.

28. Garcia JJ., et al. "Pollinosis due to Australian pine (Casuarina): An aerobiologic and clinical study in southern Spain". Allergy 52.1 (1997): 11-17.

29. Burton $\mathrm{PK}$ and Katelaris $\mathrm{CH}$. "Characteristics of the Casuarina pollen season in the Sydney District, NSW". Journal of Allergy and Clinical Immunology 119.1 (2007): S102.

30. Serhane H., et al. "Prevalence of skin sensitization to pollen of date palm in Marrakesh, Morocco". Journal of Allergy (2017): 3.

31. Damialis A., et al. "Estimating the abundance of airborne pollen and fungal spores at variable elevations using an aircraft: how high can they fly?" Scientific Reports 7 (2017): 44535.

32. Pola J., et al. "Correlation between total annual atmospheric pollen counts for Chenopodiaceae-Amaranthaceae and the prevalence of positive skin prick test to Chenopodium and/or Salsola pollen extracts: a multicenter study". Journal of Investigational Allergology and Clinical Immunology 19 (2009): 64-79.

33. De La Cruz., et al. "Analysis of Chenopodiaceae-Amaranthaceae airborne pollen in Salamanca, Spain". Turkish Journal of Botany 36 (2012): 336-343. 
34. Tiotiu A., et al. "Urtica dioica pollen allergy: Clinical, biological, and allergomics analysis". Annals of Allergy, Asthma and Immunology 117.5 (2016): 527-534.

35. Troutt $\mathrm{C}$ and Levetin E. "Correlation of spring spore concentrations and meteorological conditions in Tulsa, Oklahoma”. International Journal of Biometeorology 45 (2001): 64-74.

36. Gioulekas D., et al. "Allergenic fungi spore records (15 years) and sensitization in patients with respiratory allergy in Thessaloniki-Greece". Journal of Investigational Allergology and Clinical Immunology 14 (2004): 225-231.

37. Gómez de Ana S., et al. "Seasonal distribution of Alternaria, Aspergillus, Cladosporium and Penicillium species isolated in homes of fungal allergic patients". Journal of Investigational Allergology and Clinical Immunology 16.6 (2006): 357-363.

38. Damialis A and Gioulekas D. "Airborne allergenic fungal spores and meteorological factors in Greece: Forecasting possibilities". Grana 45.2 (2006): 122-129.

39. Menetrez, MY., et al. "An evaluation of the protein mass of particulate matter". Atmospheric Environment 41.37 (2007): 82648274.

40. Fukutomi Y and Taniguchi M. "Sensitization to fungal allergens: Resolved and unresolved issues". Allergology International 64 (2015): 321-331.

41. Sabo NC., et al. "Air Pollution by Pollen Grains of Anemophilous Species: Influence of Chemical and Meteorological Parameters". Water, Air, and Soil Pollution 226 (2015): 292.

42. Beguin H and Nolard N. "Mould biodiversity in homes. II. Air and surface analysis of 130 dwellings". Aerobiologia 10 (1994): 157-166.

43. Andersson M., et al. "Natural exposure to Alternaria spores in indices allergic rhinitis symptoms in sensitized children". Pediatric Allergy and Immunology 14.2 (2003): 100-105.

\section{Volume 4 Issue 7 July 2021}

(C) All rights are reserved by Eman M Bassiouni and Wafaa K Taia. 